Observation. - I must finally remark that some of the most rapidly fatal cases in this epidemic were unattended by spasms or cramps, and but little vomiting or purging. The patients were struck down at once. Of course the plan of treatment that $I$ have proposed can be of little or no avail in such cases. Via della Mercede, Rome, Dec. 1865.

\section{PREGNANCY IN A DWARF; TURNING AND CRANIOTOMY; RECOVERY.}

\section{Bx L. OWEN FOX, M.D., F.R.C.S.}

Ow October 6th I was called to visit a young woman, who was represented to be very ill, but the nature of the case was anknown to the messenger. The patient resided six miles from my residence, at West Dean, Wilts. On my arrival, my attention was directed to a very diminutive girl in bed, evidently suffering from great pain, coming on at intervals. The history of the case furnished me, and the symptoms, admitted no doubt of the girl being in labour. A sudden discharge of Huid from the vagina had occurred twelve hours before my arrival, followed by continual pains. The attendants had suspected the nature of the case, but it was most strongly denied by the girl. She was a good example of rickety deformity; age, seventeen; height, $3 \mathrm{ft} .7 \mathrm{in}$. Head large, 22 in. in circumference, with broad and high forehead, flat nose, and thick lips. Long bones all bent, with their extremities thickened. Length of arm, $5 \frac{1}{\mathrm{~g}} \mathrm{in}$; forearm, 5 in. Length of lower limbs, from anterior superior spine of ilium to external malleolus, $1 \mathrm{ft} .5 \mathrm{in}$. Width, from one anterior supcrior spinous process of ilium to the other, only 8 in. From symphysis pubis to anterior inferior iliac spinous process, $3 \frac{1}{2}$ in. Round pelvis, including buttocks, $28 \frac{1}{2}$ in. These measurcments were taken when she was convalescent. There was no lateral curvature of the spine, but the lower dorsal and upper lumbar portions projected backwards considerably.

On examination per vaginam the os uteri was found fully dilated, and the presenting part the left ilium, above the brim of the pelvis. This cavity was very small, and the promontory of the sacrum jutted out, contracting the brim, so that the antero-posterior diameter did not exceed two inches. As the girl had been some hours in labour, and the os uteri was fully dilated, I felt that no time should be lost in effecting delivery either by the Cæsarean operation or by craniotomy. Those who wre acquainted with country practice will be able to understand the inconvenience of being without instruments, or any assistance nearer than six or seven miles. A railway being hard by, and a train just starting for Salisbury, I availed myself of it, and was fortunate in obtaining the valuable assistance of $\mathrm{Mr}$. Wilkes, one of the surgeons to the infirmary. My son (last year's University Midwifery Scholar) was able to be present at our consultation, and we determined to try to bring down the feet. The patient having been placed fully under the influence of chloroform, after no little difficulty, and by the exercise of patience, a foot was brought down. After an hour's perseverance, the other foot, body, and arms were brought through the pelvis. Our serious difficulties now presented themselves : the occiput was resting on the pubes, and it was quite evident that the head could not pass the brim unless emptied of its contents by the perforator. To apply this instrument was no easy task, the small pelvis occupied by the neck scarcely allowing the passage of the finger. A very small portion of the right side of the occiput could be felt close to the cervical vertebre, and to this point the perforator was carefully direeted. The bone having been pierced, and the brain evacuated, traction was used, but to no purpose. By the aid of a pair of small craniotomy forceps, a portion of the occipital bone was brought away, and this allowed freer use of the crochet, \&c. Having obtained a firm hold at the base of the skull, powerful traction was made, and the head at length passed the brim. After waiting some time the placenta was extracted, the uterus firmly contracting. Two sutures were applied to a rupture of the perineum. The patient made a good recovery. The bladder lost its power for two days. The perineum had quite healed on the sixth day. On the ninth day she had two rigors, which have been the only bad symptoms; there has been no recurrence of them, and she now gets up daily.

Broughton, Winchester, Dec. 1865.

\section{ON THE ETIOLOGY OF TYPHOID FEVER.}

\section{By W. B. KESTEVEN, Esq., F.R.C.S.}

In The LANOET of Jan. 28th, among other "Interrogatories on Enteric Fever," were the following : namely-

"4. On the appearance of enteric fever in an isolated house, village, or other locality, independently of importation of the poison, stating particularly the degree of isolation, the reasons for excluding the possibility of importation, and the apparent cause of the fever.

" 5 . On the occurrence of a single case of enteric fever in a family, without any subsequent spread."

In reply thereto, I have thought that the following instances might be worth publishing, as there was conclusive evidence of their local origin, and as they did not spread their source.

Four cases of typhoid fever (with distinct rose-coloured spots and enteric symptoms) have occurred this autumn in a large, well-built house in Hornsey-lane, Highgate. Of these four cases, two terminated fatally.

It became a question how the disease could have originated in a house in an elevated and open situation, having, apparently, all the conditions favourable to good health.

There was at the time, and had been previously occasionally noticed, a drain-smell in the lower part of the house; but as the drains had been relaid with glazed pipes a few years ago, the smell was attributed to a slight defect in a watercloset. This circumstance, however, did not explain to me the occurrence of the fever in these four particular cases, out of a dozen persons inhabiting this house. Opon close inquiry, I found that these four individuals - two young ladies, who succumbed to the disease, and two servants, who have recovered-drank water almost exclusively taken from a well on the premises, while the other members of the family drank from a cistern of New River water, the latter being more ready at hand for their use, while the former was preferred, for its taste, by the young ladies. The two servants who suffered, being the attendants of these young ladies, had drunk the same water with them. My attention being thus drawn to the water-supply, the well was opened. and found to be empty; the water, it had been noticed, had been running short during the hot weather. In looking to the well we discovered-what was not before known to the occupants of the house-a large cesspool within a foot or two of the well.* The ground at this spot consists of sand lying on the plastic beds of the London clay. It seemed clear to me that the well-water had become contaminated by infiltration from this cesspool, and hence the source of the disease which proved so lamentably fatal.

I should add that I met with an isolated case of typhoid fever, in a house not far from the one already referred to during the autumn of 1864 , and that at the time I attributed this to defects in drainage; but I do not know whether there was a cesspool near the water-supply.

As bearing upon the possibility of the transmission of the poison of typhoid fever from sewage to water-supply, I beg leave to refer to a paper published in Beale's "Archives," vol. iv., in which I have given the details of an outbreak of this fever from which members of my own family were sufferers, and which I traced to contaminated water.

In all the preceding instances the disease did not spread. The same fact was observed in the case of a lad, aged thirteen, who had been sent home from a school in France. The typhoid type was well marked. There was no room to doubt the origin from sewage emanations in this instance.

During the present autumn I attended also a case of typhoid in a gentleman just returned from a Continental tour, and although a severe case, ending fatally, the disease did not spread to any other person, although the house in which he resided was in a very unfavourable position respecting its sanitary surroundings.

It is of course credible that in the first four preceding in. stances the contamination of the water-supply was not the sole exciting cause of the disease. It is possible that gaseous emanations from the sewers combined with the poison conveyed in the water to produce the disease; but the circumstances stated point so definitely to the former agency alone, and so strictly limited the operation of the fever poison, that it is not, I think, a transgression of strictly logical rules to regard these as standing in the relation of cause and effect.

Upper Holloway, Dec. 1865. 